\title{
Antimicrobial Activity of Encapsulated Mexican Oregano (Lippia berlandieri Schauer) Essential Oil Applied on Bagels
}

\author{
Aída Araceli Salgado-Nava, Ruth Hernández-Nava, Aurelio López-Malo and \\ María Teresa Jiménez-Munguía*
}

Chemical, Food and Environmental Engineering Department, Universidad de las Américas Puebla, San Andrés Cholula, Mexico

\section{OPEN ACCESS}

Edited by:

Annalisa Serio

University of Teramo, Italy

Reviewed by:

Sabu Abdulhameed,

Kannur University, India

Azila Abdul-Aziz,

University of Technology

Malaysia, Malaysia

*Correspondence:

María Teresa Jiménez-Munguía mariat.jimenez@udlap.mx

Specialty section:

This article was submitted to

Sustainable Food Processing,

a section of the journal

Frontiers in Sustainable Food Systems

Received: 22 February 2020 Accepted: 22 September 2020 Published: 23 November 2020

Citation:

Salgado-Nava AA

Hernández-Nava R, López-Malo A and Jiménez-Munguía MT (2020) Antimicrobial Activity of Encapsulated Mexican Oregano (Lippia berlandieri Schauer) Essential Oil Applied on Bagels.

Front. Sustain. Food Syst. 4:537091. doi: 10.3389/fsufs.2020.537091
Several in vitro studies of Mexican oregano essential oil (MOEO) have demonstrated its effectiveness as an antimicrobial. On the other hand, the encapsulation technique of emulsification could be used to mask the intense flavor of MOEO, protect it from physicochemical degradation, and release gradually its antimicrobial components. In the present study, emulsions were elaborated with two encapsulating agents, pectin or Arabic gum, with five concentrations of MOEO $(0 \%, 5 \%, 7.5 \%, 10 \%$, or $15 \% \mathrm{w} / \mathrm{w})$. Emulsions were characterized by density, viscosity, particle size distribution, creaming index, and peroxide index. Emulsions were applied, in a 3:1 ratio, on the surface of two formulations of bagel, one with wheat flour (BW) and another with wheat flour and oats (BWO). Bagels were characterized by water activity, moisture content, and hardness. The antimicrobial activity of MOEO encapsulated by emulsification on Penicillium expansum on the surface of the bagels was determined. In addition, a sensory analysis of the bagels was carried out using a hedonic scale. All physicochemical properties of the emulsions had a significant difference $(p<0.05)$ because of the encapsulating agent used (pectin or Arabic gum). Emulsions stabilized with Arabic gum were more stable over time than the ones with pectin. The application of the emulsions on the surface of the bagels did not show a statistical difference $(p>0.05)$ in the physicochemical properties of the breads. The growth of $P$. expansum was delayed for up to 5 or 6 days in bagels with wheat flour and Arabic gum as encapsulating agent. Both systems, BW and BWO, atomized with MOEO emulsions at high concentrations (MOEO 15\% w/w) were well accepted by the panel of judges when these were evaluated on day 0 (freshly baked bread) but not after 6 days of their elaboration.

Keywords: encapsulation, essential oil, Penicillium expansum, bagel, antimicrobial activity, sensory analysis

\section{INTRODUCTION}

In recent years, the consumption of bagels has spread from Eastern Europe to North America, and its distribution begins to be massive. In the United States, sales are estimated at $\$ 900$ million annually (Balinska, 2009). However, the shelf life of this bread is limited by several deterioration processes, one being caused by microorganisms, with Penicillium and Aspergillus being the ones with the highest incidence (Moore et al., 2008). 
Molds and yeasts are removed in the baking stage; nevertheless, once the product leaves the oven, it must be handled under sterile conditions, since recontamination by molds on the surface can occur in subsequent stages of handling (Stanley et al., 2007). Consequently, the application of numerous types of antimicrobial agents, traditionally of synthetic origin, has been used. However, the tendency of the production and consumption of foods with fewer synthetic additives is increasing (Bakry et al., 2016).

As a result, various investigations have been carried out in order to implement new food preservation technologies, among them is the application of essential oils of plants and spices, since they have been reported to have antimicrobial activity, as in the case of the essential oil of oregano [Mexican oregano essential oil (MOEO)], whose functional components are mainly carvacrol and thymol (Portillo-Ruiz et al., 2012).

However, the application of essential oils involves several problems, since, if these are applied directly to the surface of a product, the functional components can diffuse rapidly inward, subtracting protection from the surface. In addition, essential oils have a very intense flavor; consequently, a suitable technique must be selected for the implementation of the essential oils in food systems (Sandoval et al., 2004; Lakkis, 2007).

An alternative is the addition of MOEO encapsulated by emulsification; this technique allows the delay of the chemical degradation of essential oils after being exposed to environmental factors such as light, oxygen, heat, among others. It not only protects the compound of interest, this technique could be used to mask the taste, increase the shelf life of the product, or to promote the controlled release of encapsulated components (Sandoval et al., 2004; Lakkis, 2007; Bakry et al., 2016).

It is important to consider that there is little evidence of studies in the application of oil-in-water $(\mathrm{O} / \mathrm{W})$ emulsions whose core is the essential oil of spices, since most of the investigations are focused on the optimization of products such as mayonnaises, dressings, emulsified drinks, among others. Under these considerations, the general objective of this study was to evaluate the antimicrobial activity of the essential oil of Mexican oregano (Lippia berlandieri Schauer) encapsulated by emulsification on Penicillium expansum, when it is inoculated on the surface of bagels, prepared with wheat or wheat and oat flour.

\section{MATERIALS AND METHODS}

\section{Materials}

Mexican oregano (Lippia berlandieri Schauer) essential oil (MOEO) was provided by CiReNA (Natural Resources Research Center of Salaices, Lopez, Chihuahua, Mexico).

\section{Elaboration of Emulsions}

The continuous phase, $80 \%$ of the total emulsion, was formulated with different stabilizers in aqueous solutions: $1 \% \mathrm{w} / \mathrm{w}$ of Arabic gum (Boruka, Mexico) or $0.5 \% \mathrm{w} / \mathrm{w}$ of high methoxyl pectin (Reactivos Química Meyer, Mexico). The stabilizers were added slowly in water at $40^{\circ} \mathrm{C} \pm 1^{\circ} \mathrm{C}$ under constant stirring to avoid lump formation; subsequently, both solutions were sterilized at $121^{\circ} \mathrm{C}$ for $15 \mathrm{~min}$. The dispersed phase, $20 \%$ of the total emulsion, was formulated with $2.5 \% \mathrm{w} / \mathrm{w}$ of soy lecithin (Gelcaps ${ }^{\circledR}$, Mexico) and MOEO $(0 \%, 5 \%, 7.5 \%, 10 \%$, or $15 \% \mathrm{w} / \mathrm{w})$, and the rest was corn oil (La Gloria ${ }^{\circledR}$, Mexico).

An ultrasonic homogenizer (CPX-400, Cole-Parmer Instrument Company, Vernon Hills, IL, USA) was used at an intensity of $70 \%$ (corresponding to an ultrasonic wave amplitude of $84 \mu \mathrm{m}$ ) for $15 \mathrm{~min}$, under constant stirring, using a recirculation bath at $10^{\circ} \mathrm{C} \pm 1^{\circ} \mathrm{C}$, where the oil fraction was added dropwise with a sterile syringe.

\section{Characterization of Emulsions \\ Determination of Density and Viscosity}

To determine the density, Grease pycnometers were used, following the method 962.37 from the AOA (1995). A Cannon-Fenske viscometer (100, Cannon Instrument Company Inc., State College, PA, USA) was used to measure the viscosity adding $6.5 \mathrm{ml}$ of sample. The dynamic viscosity was determined (Geankoplis, 1998). The measurements were performed in triplicate.

\section{Particle Size Distribution}

A dynamic light scattering particle analyzer (Nanotrac Wave II, Microtrac Inc., Montgomeryville, PA, USA) was used to determine the particle size distribution of MOEO emulsions. The measurements were performed in triplicate. The span was calculated using the following equation (Chew and Chan, 2002) using an average of the diameters $\mathrm{D}_{10}, \mathrm{D}_{50}$, and $\mathrm{D}_{90}$, which corresponds to the particle diameter undersize $10 \%, 50 \%$, and $90 \%$ of the cumulative particle density population, respectively:

$$
\text { Span }=\frac{D_{90}-D_{10}}{D_{50}}
$$

\section{Stability of Emulsions Creaming Index}

The creaming index was determined through the technique reported by Demetriades and McClements (2000). Newly formed emulsion $(30 \mathrm{ml})$ was placed in a $45-\mathrm{ml}$ centrifuge tube. After a storage time of $24 \mathrm{~h}$ at $25^{\circ} \mathrm{C} \pm 1^{\circ} \mathrm{C}$, separation of the emulsion phases occurs, resulting in an upper cream layer and a lower serum layer. Creaming index was determined by applying the following equation:

$$
C I=\frac{H_{s}}{H_{e}} \times 100
$$

where $\mathrm{CI}$ is the creaming index (\%), $\mathrm{H}_{\mathrm{s}}$ is the height of the lower serum layer, and $\mathrm{H}_{\mathrm{e}}$ is the total height of the emulsion.

\section{Peroxide Index}

Samples were stored at $25^{\circ} \mathrm{C} \pm 1^{\circ} \mathrm{C}$ for 20 days, and the peroxide index (PI) was determined using the NMX-F-154-1987. Into an Erlenmeyer flask of $125 \mathrm{ml}, 1.0 \pm 0.05 \mathrm{~g}$ of sample and $1.0 \mathrm{~g}$ of potassium iodide (KI) were weighed. Then, $30 \mathrm{ml}$ of acetic acidchloroform solution $(3: 2)$ was added and heated in a water bath for $1 \mathrm{~min}$. Subsequently, $0.5 \mathrm{ml}$ of a $5 \% \mathrm{w} / \mathrm{w} \mathrm{KI}$ solution and $30 \mathrm{ml}$ of distilled water were added, allowing to stand for $1 \mathrm{~min}$. Then, $2 \mathrm{ml}$ of a $2 \% \mathrm{w} / \mathrm{w}$ starch solution was added, forming a brown 
TABLE 1 | Bagels formulations.

\begin{tabular}{lcc}
\hline Ingredient & Wheat (\%) & Wheat-oats (\%) \\
\hline Wheat flour & 56 & 42 \\
Water & 33 & 33 \\
Oats & 0 & 14 \\
Vegetable oil & 7 & 7 \\
Sugar & 2 & 2 \\
Yeast & 1 & 1 \\
Salt & 1 & 1 \\
\hline
\end{tabular}

color, and it was titrated with a $0.01 \mathrm{~N}$ sodium thiosulfate solution until the color of the mixture is white. Analysis was performed in triplicate on days $0,7,14$, and 21 of storage at $25^{\circ} \mathrm{C} \pm 1^{\circ} \mathrm{C}$. PI was calculated by expressing the milliequivalents of peroxides contained in a kilogram of oil using the following equation:

$$
P I=\frac{V \times N \times 1000}{m}
$$

where $\mathrm{PI}$ is the peroxide index (meq $\mathrm{O}_{2} / \mathrm{kg}$ ), $\mathrm{V}$ is the volume used for the titration $(\mathrm{ml}), \mathrm{N}$ is the Normality of the sodium thiosulfate, and $\mathrm{m}$ is the mass of the sample ( $\mathrm{g}$ ).

\section{Bagels Elaboration}

Breads were elaborated using the modified method described by Meilach (1995). The bagels formulations are shown in Table 1. The ingredients were weighed, mixed, and kneaded. Afterward, the dough was cut into portions of $40 \mathrm{~g}$, manually shaped, and fermented at $35^{\circ} \mathrm{C} \pm 1^{\circ} \mathrm{C}$ for $30 \mathrm{~min}$, with $65 \%$ relative humidity. Baking was carried out at $180^{\circ} \mathrm{C} \pm 1^{\circ} \mathrm{C}$ for $13 \mathrm{~min}$, and finally, the breads were cooled to $25^{\circ} \mathrm{C} \pm 1^{\circ} \mathrm{C}$.

\section{Atomization of Emulsions on Bagels}

The modified method described by Madjouko et al. (2019) was used. An atomizer with a $0.15-\mathrm{g}$ emulsion capacity was used. The emulsions with the different MOEO levels were applied under a laminar flow hood, placing the atomizer at $8 \mathrm{~cm}$ from the surface of each bread, letting them dry for $2 \mathrm{~min}$. It was enough time for the emulsion to be absorbed at a maximum depth of $1 \mathrm{~mm}$ inside the bread. A control system without atomization of emulsion was also tested. Breads were stored in polycarbonate plastic boxes previously disinfected with a $4.5 \%(\mathrm{v} / \mathrm{v})$ sodium hypochlorite solution. The bagels-boxes were stored at $25^{\circ} \mathrm{C} \pm 1^{\circ} \mathrm{C}$.

\section{Bagels Characterization Water Activity}

The water activity of the crust and crumb was determined. The measurement was carried out on a dew point electric hygrometer (CX-1, Decagon Devices Inc., Pullman, WA, USA), using $1 \mathrm{~g}$ of sample. Analysis was performed by triplicate on freshly baked bread (day 0$)$.

\section{Moisture Content}

It was determined following the method 44-15.02 of AACC (2000), in which the moisture is obtained after two drying processes. Analysis was performed in triplicate on freshly baked bread (day 0).

\section{Hardness}

It was determined using the method 74-09.01 of AACC (2000) using a texture-meter (TA-XT2, Texture Technologies Co., NY, USA) and Texture Expert software, v.2.65 (Stable Micro Systems, London, United Kingdom). A cylindrical probe of $149 \mathrm{~mm}$ in diameter, speed of $1.7 \mathrm{~mm} / \mathrm{s}$, and distance of $40 \%$ (10 mm), was used. The determination was performed in triplicate in pieces of bread approximately $4 \mathrm{~cm}$ in height. It was only measured in breads atomized with emulsions that were most effective in delaying the growth of $P$. expansum.

\section{Microbial Culture Preparation}

The strain of $P$. expansum was provided by the Food Microbiology Laboratory of Universidad de Las Américas Puebla, Mexico. The strain was cultivated on potato-dextrose agar (Bioxon, Mexico) and incubated at $25^{\circ} \mathrm{C} \pm 1^{\circ} \mathrm{C}$ for 7 days.

\section{Inoculation and Inhibition of Penicillium expansum}

The modified method described by Madjouko et al. (2019) was used. Mold spores were removed from the agar by washing the surface of the culture with $10 \mathrm{ml}$ of a sterile solution with $0.1 \%$ Tween $80(\mathrm{w} / \mathrm{w})$ and distilled water. The spore suspension was adjusted to contain $1.5 \times 10^{7} \mathrm{CFU} / \mathrm{ml}$; then, $40 \mu \mathrm{l}$ of the spore suspension of $P$. expansum were inoculated at four different points on the surface of each piece of bread already atomized with MOEO emulsions. Two pieces of bread of each formulation were inoculated in the same way. Bagels formulated with wheat flour or bagels with wheat-oats flour were inoculated without emulsion as control. The pieces of bread already inoculated were stored in hermetically sealed polycarbonate plastic boxes. The mold response growth was recorded as mold growth, when reaching a halo of $0.8 \mathrm{~cm}$, or as not growth otherwise. Daily observations were made for up to 15 days in each inoculated piece during storage at $25^{\circ} \mathrm{C} \pm 1^{\circ} \mathrm{C}$. For each day of observation, the fraction of mold survival was calculated out of eight inocula in total for each bread formulation and MOEO evaluated concentration.

\section{Mathematical Modeling of the Microbial Growth Probability}

Results were expressed as the growth or non-growth (1 or 0 , respectively) of $P$. expansum on two bagel formulations, bagelwheat flour (BW) and bagel-wheat flour-oats (BWO), with eight replicates recorded on each day. Data were modeled using the binary logistic regression (BLR) analysis in order to assess the probability of mold growth (between 0 and 1), depending on the following factors $(\mathrm{Xn})$ : concentration of MOEO (0\%, 5\%, 7.5\%, $10 \%$, or $15 \% \mathrm{w} / \mathrm{w}$ ), the type of encapsulating agent (Arabic gum or pectin), and the storage time (0-15 days, measured daily). The statistical package Minitab v.16 (LEAD Technologies, State College, PA, USA) was used to obtain the parameters of the BLR model, applying the logit function to calculate the probability of microbial growth. Goodness of fit test was performed using 
the Hosmer and Lemeshow test and the percentage of agreement (Dobson, 1990).

$$
\operatorname{logit}(P)=\ln \frac{P}{(1-P)}=\frac{\exp \left[\sum \beta_{0}+C_{n} X_{n}\right]}{1+\exp \left[\sum \beta_{0}+C_{n} X_{n}\right]}
$$

where $P$ is the microbial growth probability, $\beta_{0}$ is the intercept, $\mathrm{C}_{\mathrm{n}}$ is the coefficient for factor $\mathrm{n}$, and $\mathrm{X}_{\mathrm{n}}$ is the factor $\mathrm{n}$.

\section{Sensory Analysis}

It was carried out applying an affective test using a structured hedonic scale of seven points, where the level of acceptance decreases with the score. The score of 7 points corresponded to "I like it in extreme" and 0 points to "I dislike it in the extreme." A total of 25 untrained judges participated for this test (Larmond, 1982). Sensory analysis was performed using samples of freshly baked bread (day 0 ) and breads with 6 days of storage at $25^{\circ} \mathrm{C} \pm 1^{\circ} \mathrm{C}$.

\section{Statistical Analysis}

Experimental data were evaluated statistically by an analysis of variance (ANOVA) with Tukey tests (95\% confidence level), using the statistical package Minitab software v.16 (LEAD Technologies, State College, PA, USA), in order to determine if there was a significant difference between samples.

\section{RESULTS}

\section{Characterization of Emulsions}

Density of emulsions stabilized with pectin varied from 0.974 to $0.977 \mathrm{~g} / \mathrm{cm}^{3}$, while the ones stabilized with Arabic gum ranged between 0.976 and $0.980 \mathrm{~g} / \mathrm{cm}^{3}$. As shown in Table 2, the type of encapsulating agent and the concentration of oregano essential oil (MOEO) affected the density of the emulsions. It was observed that as MOEO concentration increased, the density increased as well. A significant difference $(p<0.05)$ was found among the different systems.

Results of viscosity of emulsion systems, stabilized with pectin or Arabic gum, with different MOEO concentrations are

TABLE 2 | Density of the different emulsion systems using pectin or Arabic gum as encapsulating agents at different Mexican oregano essential oil (MOEO) concentrations.

\begin{tabular}{lcc}
\hline Encapsulating agent & MOEO concentration (\%) & Density $\left(\mathbf{g} / \mathbf{c m}^{\mathbf{3}}\right)$ \\
\hline Pectin & 0 & $0.974 \pm 0.003^{\mathrm{a}}$ \\
& 5 & $0.974 \pm 0.002^{\mathrm{a}}$ \\
& 7.5 & $0.974 \pm 0.002^{\mathrm{a}}$ \\
10 & $0.976 \pm 0.003^{\mathrm{b}}$ \\
Arabic gum & 15 & $0.977 \pm 0.001^{\mathrm{b}}$ \\
& 0 & $0.976 \pm 0.003^{\mathrm{a}}$ \\
& 5 & $0.976 \pm 0.002^{\mathrm{a}}$ \\
& 7.5 & $0.976 \pm 0.002^{\mathrm{a}}$ \\
& 10 & $0.978 \pm 0.001^{\mathrm{c}}$ \\
& 15 & $0.980 \pm 0.002^{\mathrm{d}}$ \\
\hline
\end{tabular}

Different letters in the column show significant differences $(p<0.05)$ between samples. shown in Figure 1. It was observed that as the concentration of MOEO increased in the emulsion, the viscosity decreased. Regarding the encapsulating agents, emulsions stabilized with pectin showed a higher viscosity than those of Arabic gum, despite the concentration in which these were used, $0.5 \% \mathrm{w} / \mathrm{w}$ and $1 \% \mathrm{w} / \mathrm{w}$, respectively. Both the concentration of MOEO and the encapsulating agents affected the viscosity, causing a significant statistical difference $(p<0.05)$ between the systems.

The type of encapsulating agent was decisive in the particle size distribution of emulsions (Figure 2). Arabic gum produced particles with smaller diameter and a unimodal tendency, which means that the particle size of the emulsion is homogeneous. Arabic gum emulsion with a concentration of $15 \% \mathrm{w} / \mathrm{w}$ of MOEO was more homogeneous than other systems, which can be seen in its span value (Table 3 ) being close to 1 . Systems stabilized with pectin showed greater heterogeneity, which can trigger various instability factors, such as flocculation, coalescence, and phase separation. Values of $\mathrm{D}_{10}, \mathrm{D}_{50}$, and $\mathrm{D}_{90}$ were statistically different $(p<0.05)$ between systems stabilized with Arabic gum or pectin (Table 3).

\section{Stability of Emulsions}

The type of encapsulating agent was a determinant in the values obtained from creaminess. Emulsions stabilized with Arabic gum showed no level of creaminess during the days of observation; only a slight color change could be noticed, being more intense on the surface of the emulsion. As for the emulsions stabilized with pectin (Figure 3), the level of creaminess was presented from the first hours of preparation of the emulsions $(\approx 5 \mathrm{~h}$ after elaboration); it increased until reaching a value of $60 \%$ at the end of the observation (21 days). A significant statistical difference was observed $(p<0.05)$ between the systems stabilized with pectin and Arabic gum.

The number of intermediate compounds formed at the start of the lipid oxidation reaction can be determined using the PI (Asensio et al., 2011). The results of the determination are shown in Figure 4. Emulsions stabilized with Arabic gum showed more stability than the ones stabilized with pectin. After the seventh day of storage, the emulsion with Arabic gum and $15 \%$ w/w of MOEO had the lowest value of PI compared to the other systems. A significant statistical difference $(p<0.05)$ was observed among samples for values of PI.

\section{Bagels Characterization}

Since the application of the different emulsions could cause some differences in the water activity of the breads, thus affecting their stability, it was important to determine this parameter. The results of the determination of the water activity of the crust and the crumb of two bagel formulations, BW and BWO, being atomized or not with MOEO emulsions are shown in Table 4. Water activity of the crumb for the different formulations of bagels varied from 0.86 to 0.87 ; meanwhile, the values of the crust varied from 0.94 to 0.95 . No significant statistical difference ( $p$ $>0.05$ ) was found among the samples for the water activity of crumb or crust, which means that adding MOEO emulsion to the bagels did not have an effect on water activity. 


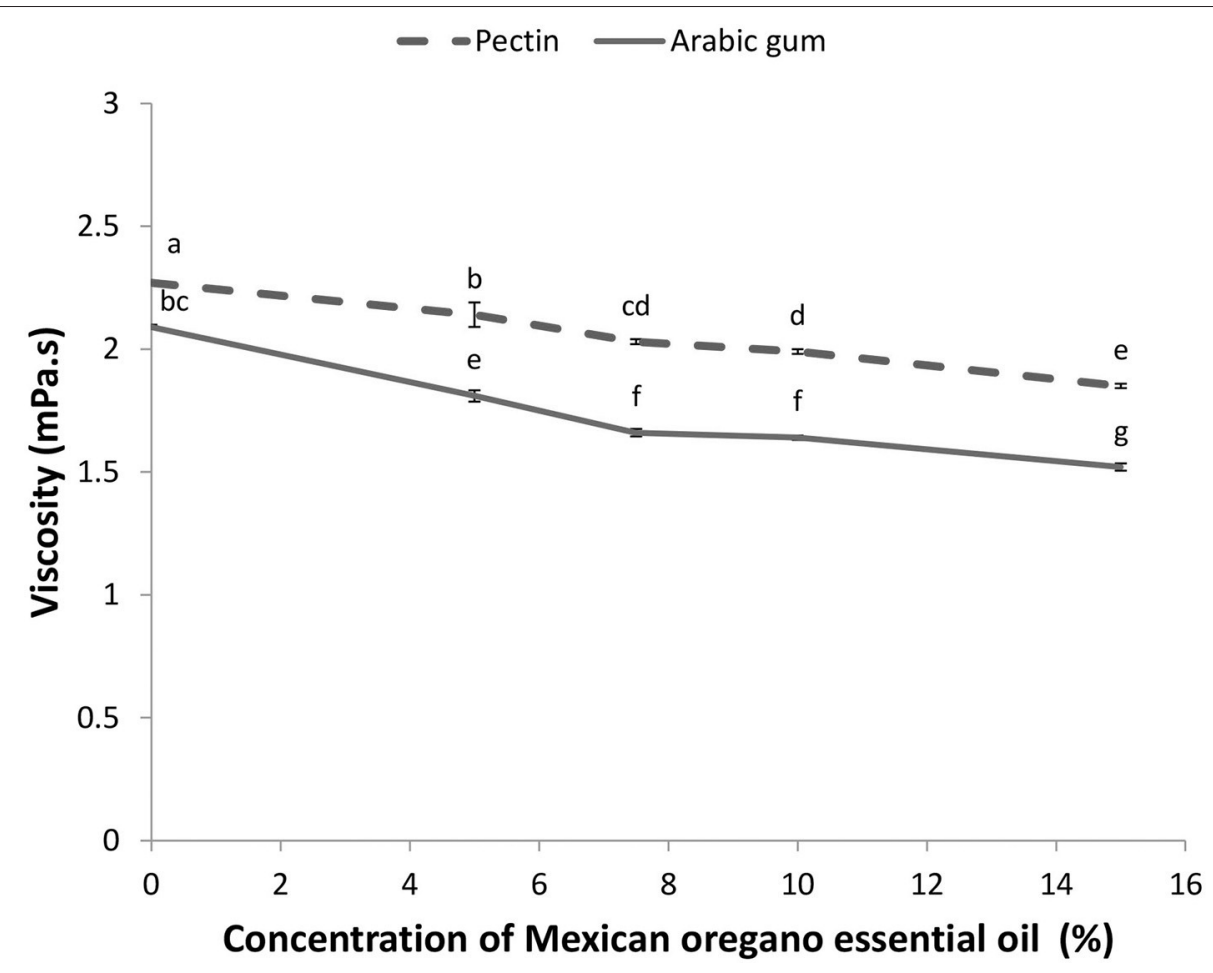

FIGURE 1 | Viscosity of the different emulsion systems using pectin or Arabic gum determined at time 0 . Arithmetic means that do not share the same letter are significantly different $(p<0.05)$.

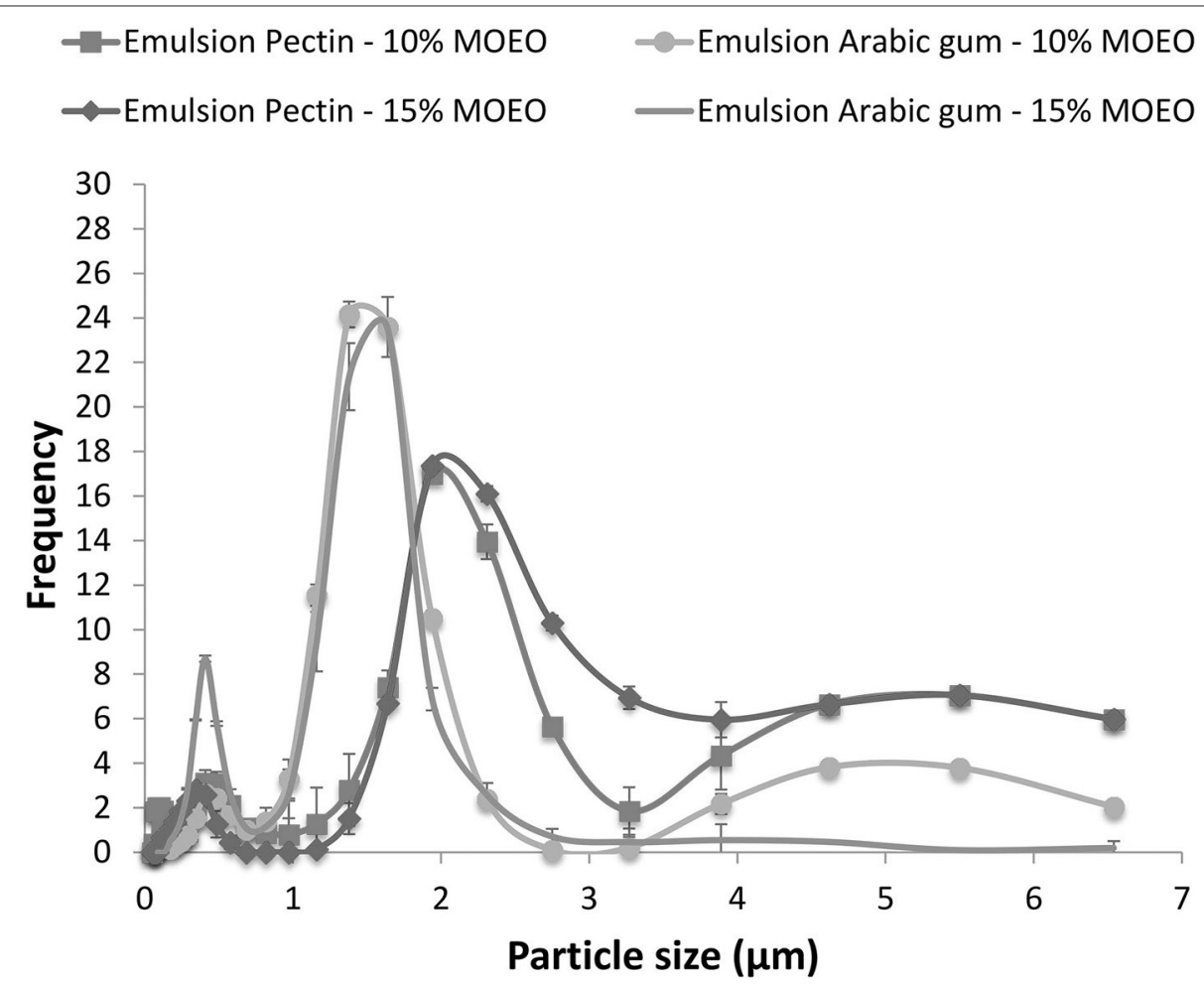

FIGURE 2 | Particle size distribution of different emulsion systems using pectin or Arabic gum with 10 and 15\% W/W of Mexican oregano essential oil (MOEO). 
TABLE 3 | Values of particle size distribution of emulsions stabilized with pectin or Arabic gum at concentrations of $10 \%$ or $15 \%$ w/w of oregano essential oil (MOEO).

\begin{tabular}{|c|c|c|c|c|c|c|}
\hline Encapsulating agent & MOEO concentration (\%) & $D_{10}(\mu \mathrm{m})$ & $\mathrm{D}_{50}(\mu \mathrm{m})$ & $D_{90}(\mu \mathrm{m})$ & Mode $(\mu \mathrm{m})$ & Span $(\mu \mathrm{m})$ \\
\hline \multirow[t]{2}{*}{ Pectin } & 10 & $0.19 \pm 0.08^{a}$ & $1.83 \pm 0.05^{a}$ & $4.99 \pm 0.64^{a}$ & 1.94 & 2.62 \\
\hline & 15 & $0.32 \pm 0.03^{b}$ & $2.13 \pm 0.19^{b}$ & $4.98 \pm 0.34^{a}$ & 1.94 & 2.19 \\
\hline \multirow[t]{2}{*}{ Arabic gum } & 10 & $0.58 \pm 0.08^{c}$ & $1.36 \pm 0.38^{c}$ & $3.81 \pm 0.47^{b}$ & 1.38 & 2.38 \\
\hline & 15 & $0.33 \pm 0.03^{b}$ & $1.23 \pm 0.19^{c}$ & $1.67 \pm 0.34^{c}$ & 1.38 & 1.08 \\
\hline
\end{tabular}

Different letters in the column show significant differences $(p<0.05)$ between samples.

Table 5 shows the values obtained for the determination of the moisture content of the crust and crumb of the two bagel formulations (BW and BWO) when applying or not the different MOEO emulsions stabilized with pectin or Arabic gum. The moisture content of the different systems ranged between $20.00 \%$ and $20.70 \%$ for the crust, while for the crumb varied between $24.66 \%$ and $25.60 \%$. No significant difference $(p>0.05)$ was found, in the moisture content in the crust or crumb, among the systems treated with different MOEO emulsions and the control system (without emulsion).

Hardness was determined only in bagels atomized with MOEO emulsions that were most effective in delaying the growth of $P$. expansum. These emulsions were the ones with $10 \%$ and $15 \% \mathrm{w} / \mathrm{w}$ of MOEO. Figure 5A shows the hardness of the two bagel formulations (BW and BWO), atomized with emulsions stabilized with pectin or Arabic gum GA with $10 \%$ w/w of MOEO, as well as the hardness of the control system (without emulsion added). In general, it was observed that the hardness of all the systems presented a bigger increase in the first 4 days, and then the increase was smaller. A statistically significant difference $(p<0.05)$ was observed with respect to the type of bread, regardless of the application of the different emulsion systems; the BWO systems being the ones that presented greater hardness than the BW systems. Only on day 0 (freshly baked bread), no significant differences ( $p>0.05$ ) were observed among the samples. Results for hardness of different formulations of bagels atomized with emulsions with $15 \%$ w/w of MOEO are shown in Figure 5B. A similar behavior with bagels atomized with emulsions with $10 \% \mathrm{w} / \mathrm{w}$ of MOEO was observed, in which only on day 0 , no significant difference $(p>0.05)$ between the different systems was found. In addition, BWO systems were the ones that had the greatest hardness since day 2 compared to BW systems, which suggest that oats promoted the bread hardening.

Regarding the application of different emulsion systems, it was found that these do not affect the hardness of the bagels, since the values obtained from the control systems (without emulsion) were close to the ones of the atomized breads. No significant statistical difference $(p>0.05)$ was observed for bagels atomized with emulsions of $10 \%$ and $15 \%$ w/w of MOEO.

\section{Inhibition of Penicillium expansum}

The results obtained from the application of emulsions stabilized with pectin or Arabic gum on the surface of bagels inoculated with $P$. expansum are shown in Table 6. MOEO encapsulated by emulsification had a low effectiveness against $P$. expansum
TABLE 4 | Water activity of crust and crumb of different formulations of bagels atomized with emulsions stabilized with pectin or Arabic gum at different concentrations of Mexican oregano essential oil (MOEO) stored at $25^{\circ} \mathrm{C}$.

\begin{tabular}{|c|c|c|c|c|}
\hline \multirow[t]{2}{*}{ System } & \multirow{2}{*}{$\begin{array}{l}\text { Encapsulating } \\
\text { agent }\end{array}$} & \multirow{2}{*}{$\begin{array}{c}\text { MOEO } \\
\text { concentration } \\
(\%)\end{array}$} & \multicolumn{2}{|c|}{ Water activity } \\
\hline & & & Crust & Crumb \\
\hline \multirow{6}{*}{$\begin{array}{l}\text { Bagel with } \\
\text { wheat flour }\end{array}$} & Pectin & Control $^{\star}$ & $0.87 \pm 0.006^{a}$ & $0.95 \pm 0.004^{b}$ \\
\hline & & 0 & $0.86 \pm 0.011^{a}$ & $0.94 \pm 0.004^{b}$ \\
\hline & & 5 & $0.87 \pm 0.001^{a}$ & $0.94 \pm 0.001^{b}$ \\
\hline & & 7.5 & $0.87 \pm 0.001^{a}$ & $0.94 \pm 0.003^{b}$ \\
\hline & & 10 & $0.87 \pm 0.002^{a}$ & $0.95 \pm 0.001^{b}$ \\
\hline & & 15 & $0.87 \pm 0.005^{a}$ & $0.94 \pm 0.003^{b}$ \\
\hline \multirow{6}{*}{$\begin{array}{l}\text { Bagel with } \\
\text { wheat flour } \\
\text { and oats }\end{array}$} & Pectin & Control $^{\star}$ & $0.87 \pm 0.007^{a}$ & $0.95 \pm 0.003^{b}$ \\
\hline & & 0 & $0.86 \pm 0.006^{a}$ & $0.95 \pm 0.001^{b}$ \\
\hline & & 5 & $0.87 \pm 0.013^{a}$ & $0.95 \pm 0.004^{b}$ \\
\hline & & 7.5 & $0.87 \pm 0.006^{a}$ & $0.95 \pm 0.001^{b}$ \\
\hline & & 10 & $0.87 \pm 0.004^{a}$ & $0.95 \pm 0.003^{b}$ \\
\hline & & 15 & $0.87 \pm 0.010^{a}$ & $0.95 \pm 0.005^{b}$ \\
\hline \multirow{6}{*}{$\begin{array}{l}\text { Bagel with } \\
\text { wheat flour }\end{array}$} & Arabic gum & Control $^{\star}$ & $0.87 \pm 0.006^{a}$ & $0.94 \pm 0.004^{b}$ \\
\hline & & 0 & $0.86 \pm 0.001^{a}$ & $0.94 \pm 0.015^{b}$ \\
\hline & & 5 & $0.86 \pm 0.006^{a}$ & $0.94 \pm 0.001^{b}$ \\
\hline & & 7.5 & $0.87 \pm 0.006^{a}$ & $0.94 \pm 0.002^{b}$ \\
\hline & & 10 & $0.87 \pm 0.013^{a}$ & $0.95 \pm 0.005^{b}$ \\
\hline & & 15 & $0.86 \pm 0.007^{a}$ & $0.94 \pm 0.005^{b}$ \\
\hline \multirow{6}{*}{$\begin{array}{l}\text { Bagel with } \\
\text { wheat flour } \\
\text { and oats }\end{array}$} & Arabic gum & Control $^{*}$ & $0.87 \pm 0.014^{a}$ & $0.95 \pm 0.005^{b}$ \\
\hline & & 0 & $0.86 \pm 0.016^{a}$ & $0.95 \pm 0.012^{b}$ \\
\hline & & 5 & $0.87 \pm 0.004^{a}$ & $0.95 \pm 0.005^{b}$ \\
\hline & & 7.5 & $0.87 \pm 0.007^{a}$ & $0.95 \pm 0.006^{b}$ \\
\hline & & 10 & $0.87 \pm 0.021^{a}$ & $0.95 \pm 0.002^{b}$ \\
\hline & & 15 & $0.87 \pm 0.011^{a}$ & $0.94 \pm 0.013^{b}$ \\
\hline
\end{tabular}

${ }^{*}$ Control system was without emulsion added.

Different letters in the column show significant differences $(p<0.05)$ between samples.

in both bagel systems (BW and BWO), since only at high concentrations, $10 \%$ and $15 \%$ w/w of MOEO, could the growth of this mold be delayed.

For bagels (BW and BWO) atomized with an emulsion of $0 \% \mathrm{w} / \mathrm{w}$ of MOEO, and without emulsion added, the growth of $P$. expansum was delayed until 4 days. Emulsions of $10 \% \mathrm{w} / \mathrm{w}$ of MOEO delayed the growth of $P$. expansum until 7 and 9 days using pectin or Arabic gum, respectively. As for emulsions of $15 \%$ w/w of MOEO, stabilized with pectin or Arabic gum, 


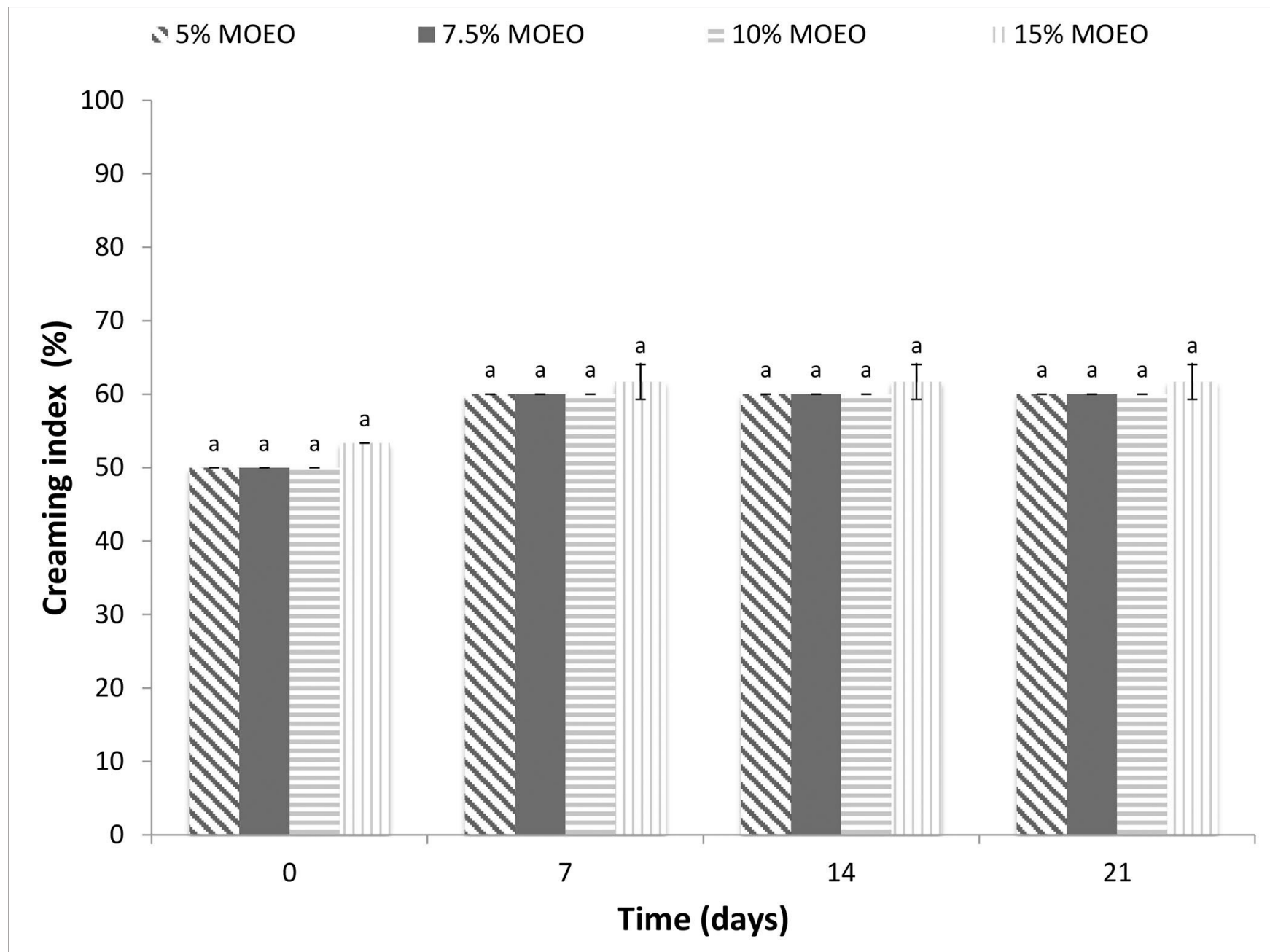

FIGURE 3 | Creaming index of emulsions stabilized with pectin at different concentrations of Mexican oregano essential oil (MOEO), stored at $25^{\circ} \mathrm{C}$, during 21 days of observation. Systems that do not share the same letter at each time are significantly different $(p<0.05)$.

the growth of $P$. expansum was delayed until 8 and 10 days, respectively. Therefore, MOEO encapsulated with Arabic gum was more effective in delaying the growth of $P$. expansum.

A significant statistical difference $(p<0.05)$ was observed between samples regarding three aspects: the concentration of MOEO, the type of encapsulating agent, and the formulation of the bagel (only BW bagels with emulsions stabilized with Arabic gum and $7.5 \%, 10 \%$, and $15 \% \mathrm{w} / \mathrm{w}$ of MOEO).

\section{Mathematical Modeling of the Probability of Microbial Growth}

Parameters for the binary logistic regression models were obtained for the microbial growth of $P$. expansum on the bagels' surface of two different formulations BW and BWO atomized with MOEO emulsions stabilized with pectin or Arabic gum (Table 7). For the formulation of BW, the factors that had a significant difference $(p<0.05)$ were the concentration of MOEO, time, and its interaction (concentration of MOEO * time); meanwhile, the factors that had a significant difference $(p<0.05)$ for the BWO formulation were the concentration of MOEO, time, encapsulating agent, and the interaction of concentration of $\mathrm{MOEO} *$ time. The goodness of fit using the Hosmer and Lemeshow test had a chi-square of 0.999 and a percentage of agreement of $98.8 \%$ for the model of the formulation $\mathrm{BW}$; as for the formulation of $\mathrm{BWO}$, these values were 0.848 and $98.9 \%$, respectively.

Figure 6 shows the growth probability fitted model of $P$. expansum when different concentrations of MOEO emulsions were atomized on the surface of two bagel formulations (BW and BWO) through the storage period at $25^{\circ} \mathrm{C}$.

\section{Sensory Analysis}

Results of the sensory analysis for different bagels formulations (BW and BWO) atomized with emulsions stabilized with pectin or Arabic gum and $10 \% \mathrm{w} / \mathrm{w}$ of MOEO, evaluated at different times, for freshly baked bread (day 0) and after 6 days are presented in Figure 7A. Freshly baked breads of BW had a general acceptability of 6 points (equivalent to "I like it very 


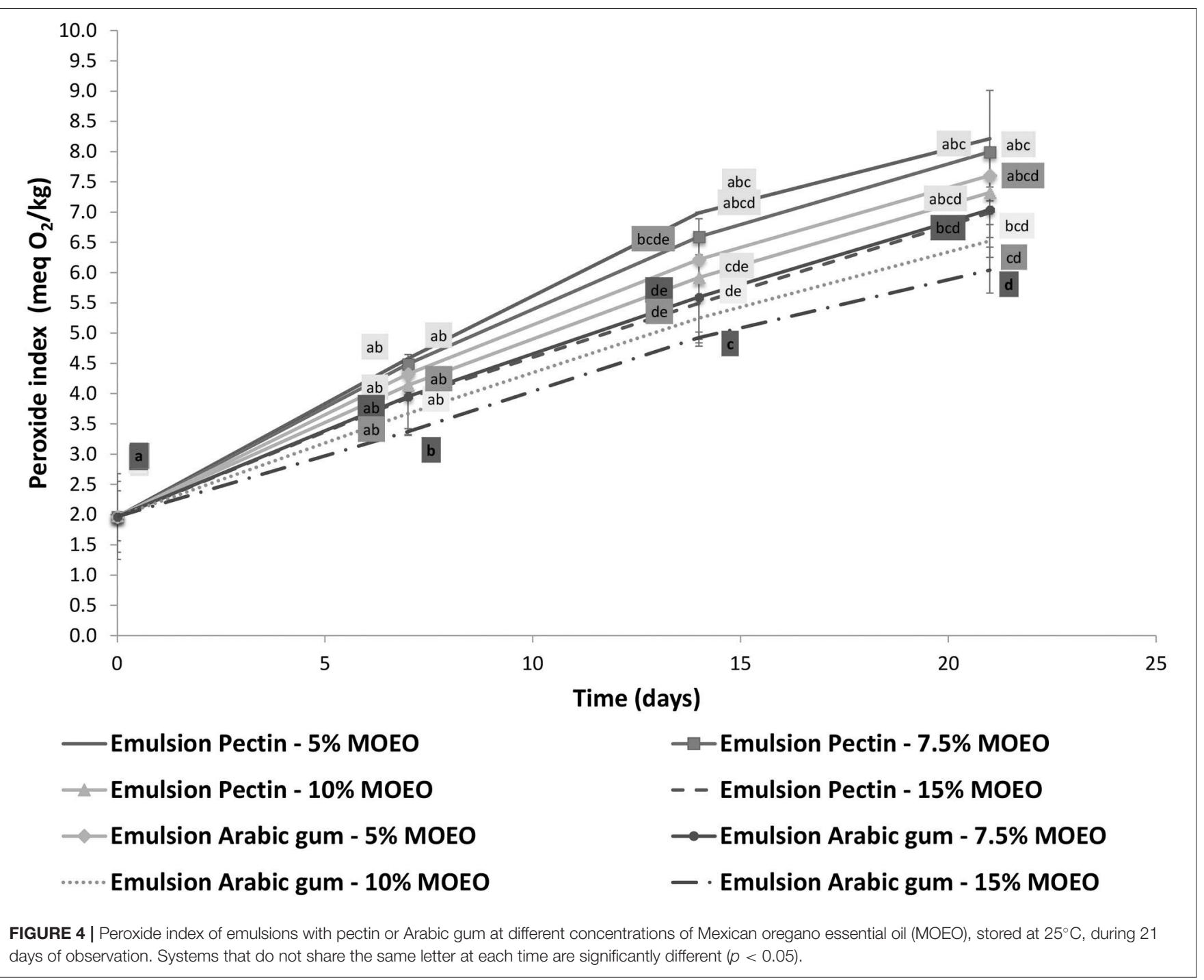

much"), while BWO breads had 5.5 points ("I like it very much"/"I like it moderately"). BW and BWO systems (freshly baked bread) atomized with emulsions stabilized with pectin or Arabic gum had no significant difference $(p>0.05)$ between samples. When these bagels were evaluated after 6 days of elaboration, there was no significant difference $(p>0.05)$ between both emulsion systems (pectin or Arabic gum). The scores granted by the judges were very heterogeneous depending on the aspect evaluated (Figure 7A). A significant difference was found $(p<0.05)$ with respect to the number of days after the breads were made (evaluation on days 0 and 6) of both BW and BWO bread systems atomized with the two types of MOEO emulsions (pectin or Arabic gum). The appearance was the best evaluated, "moderately liking," which means that in bread aging, it is the least obvious aspect. The smell and flavor were perceived as "I do not like or dislike," but the texture was what was evaluated as "moderately dislike." However, the general acceptability was 4 points corresponding to "I do not like or dislike." Therefore, bagels atomized with MOEO emulsions stabilized with pectin or Arabic gum were no longer wellaccepted by the judges, since their sensory characteristics were affected, specially the texture.

Figure 7B shows the results of the sensorial analysis for different bagels formulations (BW and BWO) atomized with emulsions stabilized with pectin or Arabic gum and 15\% w/w of MOEO, evaluated at different times, for freshly baked bread (day 0$)$ and after 6 days. No significant difference $(p>0.05)$ was found between the application of emulsions stabilized with pectin or Arabic gum, neither between the bagel systems (BW and BWO) when these were evaluated freshly made. In addition, these presented almost the same level of acceptance as that of breads with emulsions of $10 \% \mathrm{w} / \mathrm{w}$ of MOEO. However, BWO systems atomized with emulsions stabilized with Arabic gum, after 6 days of being made, were perceived by the panel of judges similarly as those evaluated on day 0 ; no statistical difference $(p>0.05)$ between these bagel systems was found. 
TABLE 5 | Percentage of moisture content (w.b.) of crust and crumb of different formulations of bagels atomized with emulsions stabilized with pectin or Arabic gum at different concentrations of Mexican oregano essential oil (MOEO) stored at $25^{\circ} \mathrm{C}$.

\begin{tabular}{|c|c|c|c|c|}
\hline \multirow[t]{2}{*}{ System } & \multirow{2}{*}{$\begin{array}{l}\text { Encapsulating } \\
\text { agent }\end{array}$} & \multirow{2}{*}{$\begin{array}{c}\text { MOEO } \\
\text { concentration } \\
(\%)\end{array}$} & \multicolumn{2}{|c|}{$\%$ Moisture content (w.b) } \\
\hline & & & Crust & Crumb \\
\hline \multirow{6}{*}{$\begin{array}{l}\text { Bagel with } \\
\text { wheat flour }\end{array}$} & Pectin & Control* $^{\star}$ & $20.07 \pm 0.18^{a}$ & $24.34 \pm 0.49^{b}$ \\
\hline & & 0 & $20.60 \pm 0.13^{a}$ & $24.22 \pm 0.26^{b}$ \\
\hline & & 5 & $20.32 \pm 0.13^{a}$ & $24.23 \pm 0.35^{b}$ \\
\hline & & 7.5 & $20.10 \pm 0.16^{a}$ & $24.13 \pm 0.19^{b}$ \\
\hline & & 10 & $20.41 \pm 0.30^{a}$ & $24.34 \pm 0.32^{b}$ \\
\hline & & 15 & $20.32 \pm 0.01^{a}$ & $24.45 \pm 0.79^{b}$ \\
\hline \multirow{6}{*}{$\begin{array}{l}\text { Bagel with } \\
\text { wheat flour } \\
\text { and oats }\end{array}$} & Pectin & Control* $^{*}$ & $20.20 \pm 0.30^{a}$ & $25.28 \pm 0.12^{b}$ \\
\hline & & 0 & $20.47 \pm 0.08^{a}$ & $24.99 \pm 0.47^{b}$ \\
\hline & & 5 & $20.05 \pm 0.08^{a}$ & $25.01 \pm 0.47^{b}$ \\
\hline & & 7.5 & $20.11 \pm 0.15^{a}$ & $25.29 \pm 0.08^{b}$ \\
\hline & & 10 & $20.28 \pm 0.23^{a}$ & $25.33 \pm 0.23^{b}$ \\
\hline & & 15 & $20.32 \pm 0.13^{a}$ & $25.21 \pm 0.43^{b}$ \\
\hline \multirow{6}{*}{$\begin{array}{l}\text { Bagel with } \\
\text { wheat flour }\end{array}$} & Arabic gum & Control* $^{\star}$ & $20.46 \pm 0.50^{a}$ & $24.66 \pm 0.62^{b}$ \\
\hline & & 0 & $20.05 \pm 0.08^{a}$ & $24.86 \pm 1.08^{b}$ \\
\hline & & 5 & $20.14 \pm 0.40^{a}$ & $24.81 \pm 0.23^{b}$ \\
\hline & & 7.5 & $20.38 \pm 0.09^{a}$ & $24.65 \pm 0.05^{b}$ \\
\hline & & 10 & $20.35 \pm 0.35^{a}$ & $24.98 \pm 0.21^{b}$ \\
\hline & & 15 & $20.34 \pm 0.50^{a}$ & $24.77 \pm 0.14^{b}$ \\
\hline \multirow{6}{*}{$\begin{array}{l}\text { Bagel with } \\
\text { wheat flour } \\
\text { and oats }\end{array}$} & Arabic gum & Control $^{*}$ & $20.72 \pm 0.10^{a}$ & $25.54 \pm 0.07^{b}$ \\
\hline & & 0 & $20.74 \pm 0.19^{a}$ & $24.87 \pm 0.65^{b}$ \\
\hline & & 5 & $20.59 \pm 0.54^{a}$ & $25.50 \pm 0.53^{b}$ \\
\hline & & 7.5 & $21.16 \pm 0.25^{a}$ & $25.25 \pm 0.21^{b}$ \\
\hline & & 10 & $20.82 \pm 0.36^{a}$ & $25.50 \pm 0.14^{b}$ \\
\hline & & 15 & $20.21 \pm 0.15^{a}$ & $25.41 \pm 0.72^{b}$ \\
\hline
\end{tabular}

${ }^{*}$ Control system was without emulsion added.

Different letters in the column show significant differences $(p<0.05)$ between samples.

\section{DISCUSSION}

\section{Characterization of Emulsions}

The increase observed in the density as the oregano essential oil (MOEO) increased could be due to the density of the MOEO that is slightly higher than the one of vegetable oil (Briceño and Navas, 2005). Regarding the effect of the type of the encapsulating agent, the difference is attributed to the fact that the amount of Arabic gum in the formulation is greater than the one of pectin, being $1 \%$ and $0.5 \% \mathrm{w} / \mathrm{w}$, respectively. Therefore, it was expected that by increasing the quantity of solids in the system, the value in density would increase as well. This effect can be observed in the report by Moreno (2011), who obtained values of 1.111 to 1.114 $\mathrm{g} / \mathrm{cm}^{3}$ of oil-in-water $(\mathrm{O} / \mathrm{W})$ emulsions with $4.7 \% \mathrm{w} / \mathrm{w}$ of olive oil, stabilized with maltodextrin at $30 \% \mathrm{w} / \mathrm{w}$.

The decrease observed in the viscosity as MOEO increased is attributed to the difference in viscosities between both oils, since corn oil has a viscosity of approximately $50.7 \mathrm{mPa} . \mathrm{s}$, being higher than that of the one of MOEO, which is $13.8 \mathrm{mPa} . \mathrm{s}$
(Ortuño, 2006). Therefore, systems with $0 \% \mathrm{w} / \mathrm{w}$ of MOEO showed the highest viscosity, and systems with $15 \% \mathrm{w} / \mathrm{w}$ of MOEO had the lowest values. Results observed with higher viscosity for emulsions stabilized with pectin than the ones stabilized with Arabic gum agree with the ones reported by other authors that indicated that Arabic gum develops a low viscosity compared to other gums (Dziezak, 1991; Djordjevic et al., 2007; López et al., 2009; Charoen et al., 2011; Qian et al., 2011).

In general, viscosity of the emulsions was like the one of whole milk, which ranges between 1.75 and $2.27 \mathrm{mPa}$.s (Cosme et al., 1997). Janiszewska and Witrowa-Rajchert (2009) determined the viscosity of rosemary essential oil emulsions with $30 \% \mathrm{w} / \mathrm{w}$ of maltodextrin-Arabic gum (3:1) and obtained a value of 103 $\mathrm{mPa}$.s. These differences in the values of viscosity could be due to the low concentration of Arabic gum used in this study compared to those used by previous authors.

Values of $\mathrm{D}_{50}$ obtained for emulsions stabilized with Arabic gum were very similar to those reported by Djordjevic et al. (2007), who reported $\mathrm{a} \mathrm{dv}_{4,3}$ of $1.1 \mu \mathrm{m}$ with $\mathrm{O} / \mathrm{W}$ emulsions using $1 \%$ of Arabic gum. Güzey and McClements (2006) obtained a $\mathrm{dv}_{4,3}$ of $4 \mu \mathrm{m}$ with $\mathrm{O} / \mathrm{W}$ emulsions stabilized with $\beta$-lactoglobulin $(0.5 \% \mathrm{w} / \mathrm{w})$ and pectin $(0.4 \% \mathrm{w} / \mathrm{w})$, whose value was higher than those observed in the present study. This difference may be due to the interaction with the encapsulating agents used for each study.

It can be inferred that the results obtained in the present study are due to the difference in protein fraction contained in pectin and Arabic gum, being greater in the latter. It has been reported that the emulsifying capacity of both encapsulating agents is largely due to their protein content (in conditions with a tendency to neutrality, $\mathrm{pH} \approx 6$ ). In addition, it has been reported that, during homogenization, proteins tend to be absorbed at the interface of oil drops, faster than polysaccharides, and consequently, these could form smaller drop sizes (Leroux et al., 2003; McClements, 2005). However, the emulsifying properties of Arabic gum have also been related to other factors such as its ability to reduce the surface tension of the oil drop interface, as well as to stabilize through steric interactions (being more effective than electrostatic interactions) between the nitrogenous fraction that contains the Arabic gum and the oil droplets. Therefore, during the homogenization, a membrane is produced in the negatively charged hydrophilic interface, providing stability to the emulsions, Arabic gum being an effective stabilizer (Leroux et al., 2003; McClements, 2005; Phillips and Williams, 2009).

\section{Stability of Emulsions}

The levels of creaming index of $0 \%$ MOEO emulsions stabilized with Arabic gum agree with the observations reported by Charoen et al. (2011) with $\mathrm{O} / \mathrm{W}$ emulsions using 10\% w/w of Arabic gum at different values of $\mathrm{pH}$. Güzey and McClements (2006) reported a creaming index of $60 \%$ for $\mathrm{O} / \mathrm{W}$ emulsions, stabilized with $\beta$-lactoglobulin $(0.5 \% \mathrm{w} / \mathrm{w})$ and pectin $(0.4 \%$ $\mathrm{w} / \mathrm{w})$, getting similar results as the pectin-stabilized system for this present study. Therefore, more stability for the emulsions was achieved using Arabic gum as encapsulating agent than with pectin, since the stability is bigger as a low 


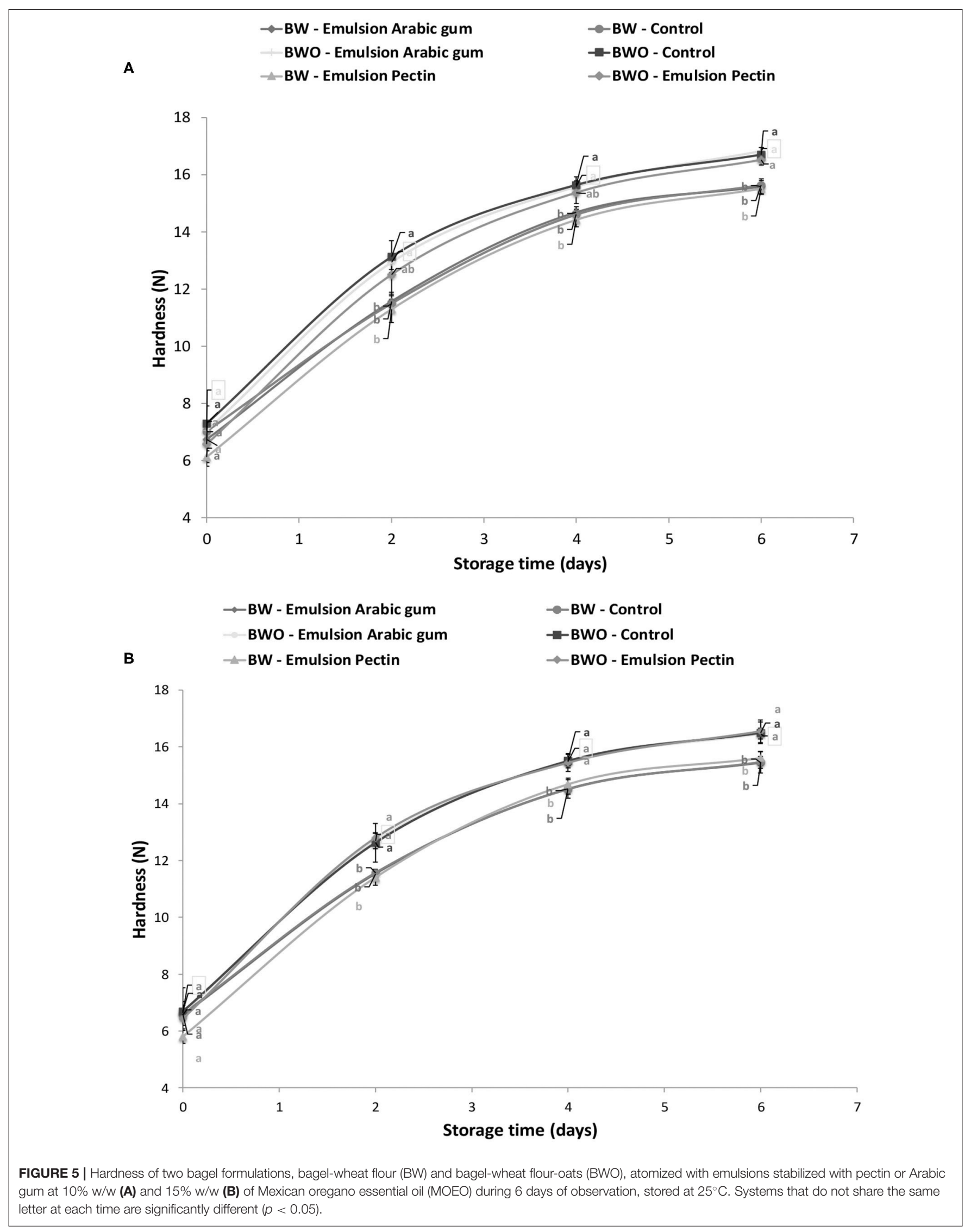


TABLE 6 | Growth of Penicillium expansum, represented as fractions of mold growth from eight inocula $\left(1.5 \times 10^{7} \mathrm{CFU} / \mathrm{ml}\right.$, each), when emulsions with different concentrations of Mexican oregano essential oil (MOEO) stabilized with pectin or Arabic gum were applied on the surface of different bagel formulations during storage at $25^{\circ} \mathrm{C}$.

\begin{tabular}{|c|c|c|c|c|c|c|c|c|c|c|c|c|c|c|c|c|c|}
\hline System & Encapsulating agent & MOEO concentration (\%) & \multicolumn{15}{|c|}{ Time (days) } \\
\hline BW & - & Control* $^{*}$ & 0 & 0 & 0 & 0 & 0.1 & 0.6 & 0.9 & 1 & 1 & 1 & 1 & 1 & 1 & 1 & 1 \\
\hline BWO & - & Control $^{\star}$ & 0 & 0 & 0 & 0 & 0.4 & 0.9 & 1 & 1 & 1 & 1 & 1 & 1 & 1 & 1 & 1 \\
\hline BW & Pectin & 0 & 0 & 0 & 0 & 0 & 0 & 0 & 0 & 0.9 & 1 & 1 & 1 & 1 & 1 & 1 & 1 \\
\hline BWO & Pectin & 0 & 0 & 0 & 0 & 0 & 0 & 0.1 & 0.5 & 1 & 1 & 1 & 1 & 1 & 1 & 1 & 1 \\
\hline BW & Pectin & 5 & 0 & 0 & 0 & 0 & 0 & 0 & 0 & 0.5 & 0.9 & 1 & 1 & 1 & 1 & 1 & 1 \\
\hline BWO & Pectin & 5 & 0 & 0 & 0 & 0 & 0 & 0 & 0 & 0.5 & 1 & 1 & 1 & 1 & 1 & 1 & 1 \\
\hline BW & Arabic gum & 5 & 0 & 0 & 0 & 0 & 0 & 0 & 0 & 0 & 0.4 & 0.6 & 1 & 1 & 1 & 1 & 1 \\
\hline BWO & Arabic gum & 5 & 0 & 0 & 0 & 0 & 0 & 0 & 0 & 0 & 0.5 & 0.8 & 1 & 1 & 1 & 1 & 1 \\
\hline BW & Pectin & 7.5 & 0 & 0 & 0 & 0 & 0 & 0 & 0 & 0 & 0 & 0.4 & 0.6 & 0.9 & 1 & 1 & 1 \\
\hline BW & Pectin & 10 & 0 & 0 & 0 & 0 & 0 & 0 & 0 & 0 & 0.1 & 0.4 & 0.8 & 1 & 1 & 1 & 1 \\
\hline BWO & Pectin & 10 & 0 & 0 & 0 & 0 & 0 & 0 & 0 & 0 & 0.1 & 0.5 & 0.9 & 1 & 1 & 1 & 1 \\
\hline BW & Arabic gum & 10 & 0 & 0 & 0 & 0 & 0 & 0 & 0 & 0 & 0 & 0 & 0.3 & 0.9 & 1 & 1 & 1 \\
\hline BWO & Arabic gum & 10 & 0 & 0 & 0 & 0 & 0 & 0 & 0 & 0 & 0 & 0 & 0.8 & 1 & 1 & 1 & 1 \\
\hline BW & Pectin & 15 & 0 & 0 & 0 & 0 & 0 & 0 & 0 & 0 & 0 & 0.1 & 0.5 & 0.9 & 1 & 1 & 1 \\
\hline BWO & Pectin & 15 & 0 & 0 & 0 & 0 & 0 & 0 & 0 & 0 & 0 & 0.3 & 0.6 & 0.9 & 1 & 1 & 1 \\
\hline BW & Arabic gum & 15 & 0 & 0 & 0 & 0 & 0 & 0 & 0 & 0 & 0 & 0 & 0 & 0.4 & 0.9 & 1 & 1 \\
\hline BWO & Arabic gum & 15 & 0 & 0 & 0 & 0 & 0 & 0 & 0 & 0 & 0 & 0 & 0 & 0.9 & 1 & 1 & 1 \\
\hline
\end{tabular}

${ }^{*}$ Control system was without emulsion added.

BW, bagel with wheat flour; BWO, bagel with wheat flour and oats.

TABLE 7 | Parameters of the binary logistic regression model obtained for two formulations of bagels.

\begin{tabular}{|c|c|c|c|c|c|}
\hline Formulation & Factors & Evaluated intervals & Coefficient & Standard error & Significance $(\mathrm{P})$ \\
\hline \multicolumn{6}{|c|}{ Bagel with wheat flour } \\
\hline & Constant & - & -11.575 & 1.715 & 0.000 \\
\hline & Time (days) & $0-15$ & 1.850 & 0.222 & 0.000 \\
\hline & Encapsulating agent & Pectin or Arabic gum & -0.036 & 0.577 & 0.950 \\
\hline \multicolumn{6}{|c|}{ Bagel with wheat flour and oats } \\
\hline & Constant & - & -10.346 & 1.658 & 0.000 \\
\hline & MOEO concentration (\%) & $0-15$ & -1.082 & 0.206 & 0.000 \\
\hline & Time (days) & $0-15$ & 2.128 & 0.265 & 0.000 \\
\hline & Encapsulating agent & Pectin or Arabic gum & -1.481 & 0.380 & 0.000 \\
\hline
\end{tabular}

MOEO, Mexican oregano essential oil.

percentage of creaminess is obtained. The low creaming index guarantees the encapsulation efficiency of the essential oil and its appropriate delivery to express its antimicrobial properties (Dávila-Rodríguez, 2020).
Paraskevopoulou et al. (2007) made a study of olive oil-lemon juice emulsions stabilized with Arabic gum, monitoring the PI for 175 days, obtaining values of PI of $<20 \mathrm{meq} \mathrm{O}_{2} / \mathrm{kg}$ after 50 days of storage. On the other hand, Asensio et al. (2011) 


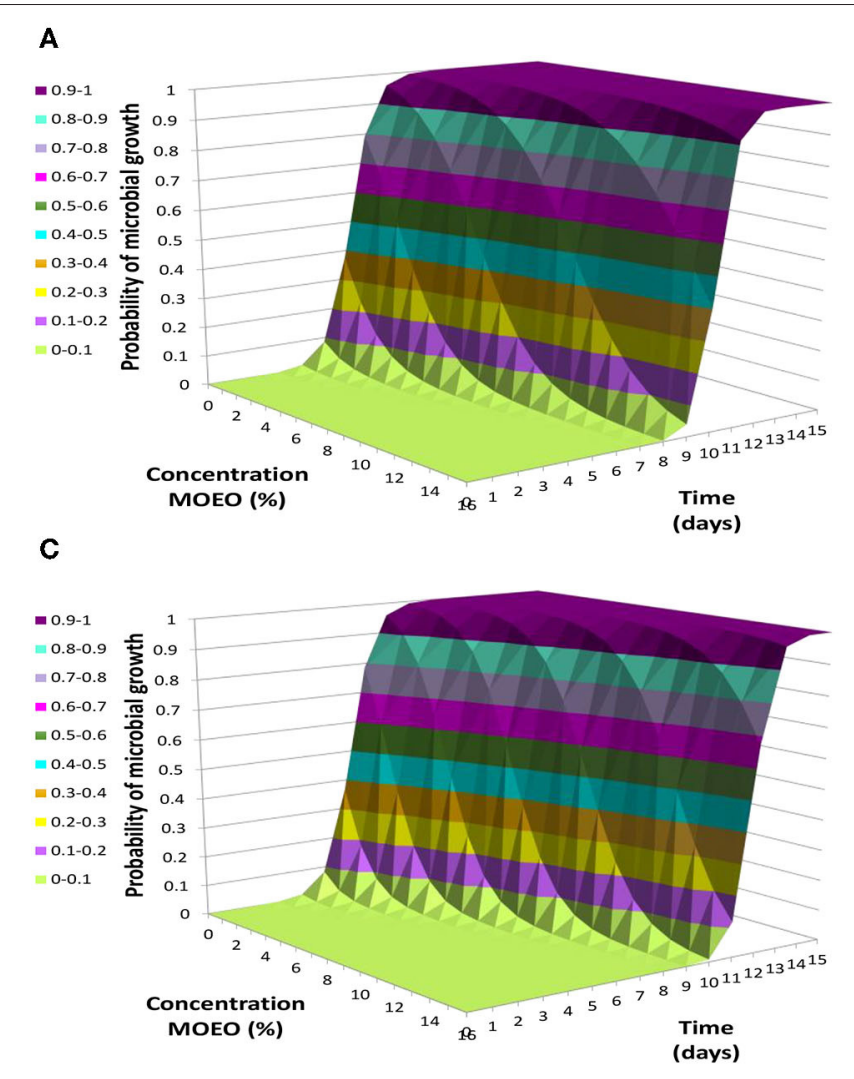

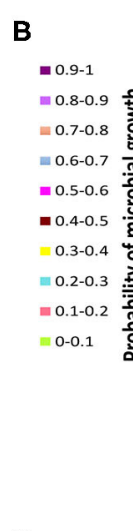

D

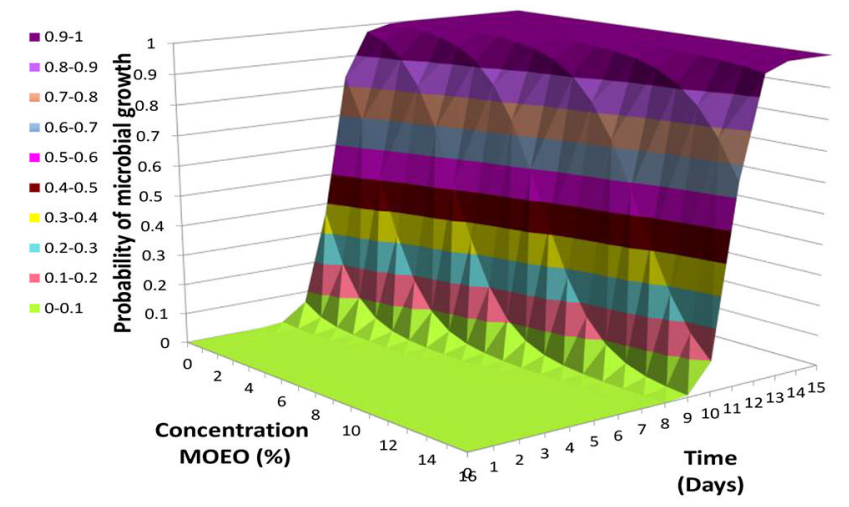

FIGURE 6 | Growth probability of Penicillium expansum (1.5 × 10 $\mathrm{CFU} / \mathrm{ml})$ when spraying emulsions at different concentrations of Mexican oregano essential oil (MOEO) on the surface of two bagel formulations with respect to time, obtained by applying the binary logistic regression model. Emulsion stabilized with pectin + bagel-wheat flour (A); emulsion stabilized with pectin + bagel-wheat flour-oats (B); emulsion stabilized with Arabic gum + bagel-wheat flour (C); emulsion stabilized with Arabic gum + bagel-wheat flour-oats (D).

reported that MOEO delays the oxidation process in olive oil, thus prolonging its shelf life. In their study, the PI obtained from oil samples exposed to darkness at $23^{\circ} \mathrm{C}$ with the addition of $0.05 \% \mathrm{w} / \mathrm{w}$ MOEO was $<15 \mathrm{meq}_{2} / \mathrm{kg}$ after 21 days of storage. These reported values were similar to the ones observed in the present study, since the PI value for the systems stabilized with pectin or Arabic gum was $<10 \mathrm{meq}_{2} / \mathrm{kg}$ after 20 days of storage. The effect of MOEO in retarding the oxidation process of oils is attributed to the antioxidant capacity, primarily to carvacrol present in MOEO (Chaquilla et al., 2007).

\section{Bagels Characterization}

According to Robertson (2003), water activity in breads varies from 0.95 to 0.99 . These values agree with the ones obtained for the crust in the two bagel formulations, BW and BWO, that varied from 0.94 to 0.95 . Baik and Chinachoti (2000) reported values of water activity for white bread of 0.96 for crumb only, and 0.94 for bread with crust, stored after 1 day at $25^{\circ} \mathrm{C}$. The same behavior was observed in the present study, in which water activity was higher in the crumb than in the crust. This is expected since the water activity in the crust is lower due to the temperature in the baking process. After several days of storage, water redistribution occurs in the bread, in which moisture of the crumb decreases as the moisture of the crust increases because of the moisture gradient between crust and crumb that tends to equilibrate during storage (Piazza and Masi, 1995; Baik and Chinachoti, 2000).

The value of water activity obtained allows $P$. expansum to grow on the crust of the studied bagels, since the minimum water activity for its growth is 0.83 and the optimal temperature for its proliferation is at $21^{\circ} \mathrm{C}$ (Barbosa-Cánovas et al., 2007).

Similar results of no significant difference in the moisture content, as the ones obtained in the present study, were reported by Sanz (2011), who worked on breads made from the mixture of amaranth flour and wheat flour (1:1 to 3:1 mass ratio). Baik and Chinachoti (2000) reported values of moisture content for white bread of $39 \%$ (d.b.) for crumb only, and $37.5 \%$ (d.b.) for bread with crust, stored after 1 day at $25^{\circ} \mathrm{C}$. These results are higher than the ones obtained in the present study, which could be due to the different formulations and processes to make the breads. However, Baik and Chinachoti (2000) observed the same behavior in which moisture content was higher in the crumb than in the crust. Like water activity, this behavior is the result of the temperature during the baking process.

A behavior similar to the one observed in the present study for the hardness of breads was reported by Sanz (2011), who 
A

$$
\begin{aligned}
& \text { BW - Emulsion Arabic gum - day } 0 \\
& \text { || BW - Emulsion Arabic gum - day } 6 \\
& =\text { BW - Emulsion Pectin - day } 0 \\
& \approx \text { BW - Emulsion Pectin - day } 6
\end{aligned}
$$

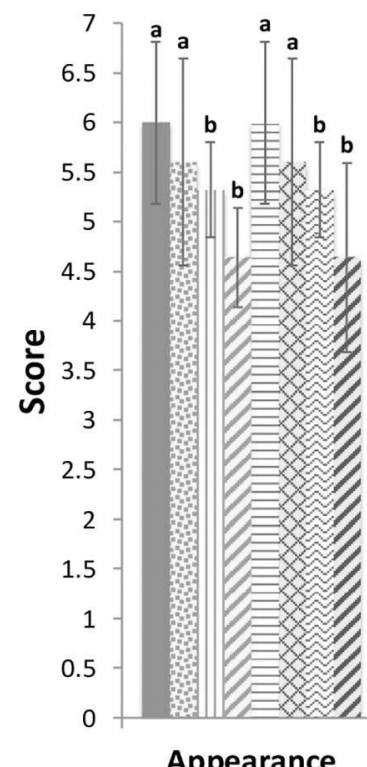

Appearance

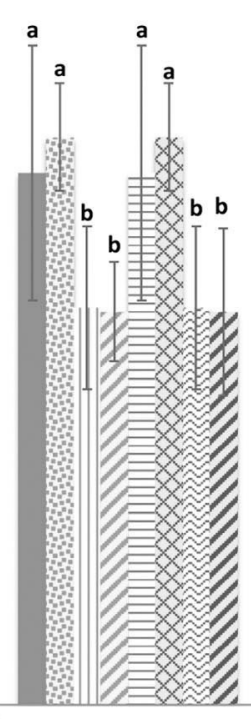

Smell

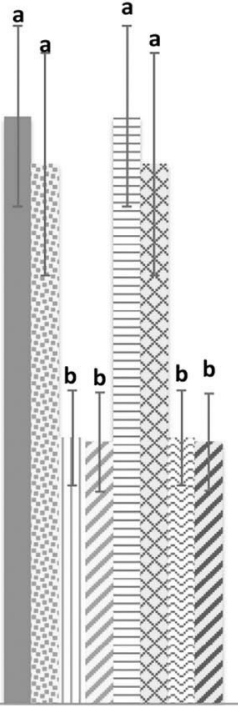

Texture
BWO - Emulsion Arabic gum - day 0

BWO - Emulsion Arabic gum - day 6

$\approx$ BWO - Emulsion Pectin - day 0

C. BWO - Emulsion Pectin - day 6

(1)

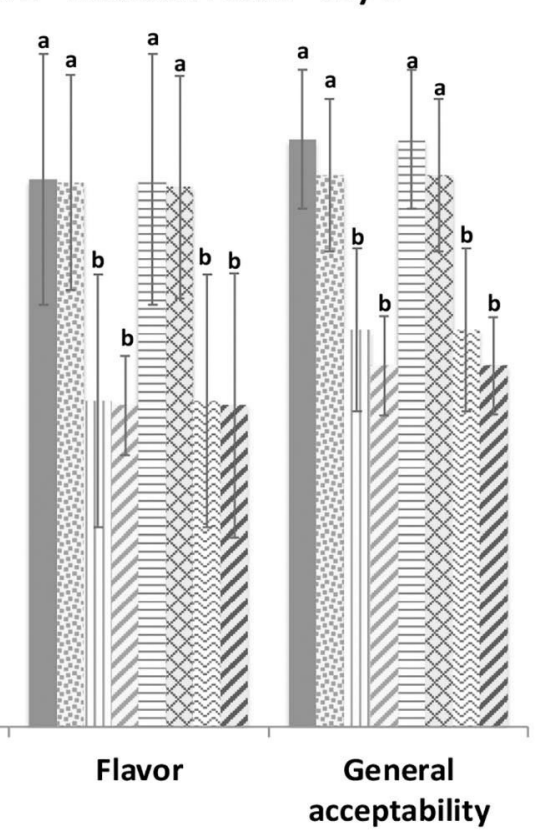

B

$$
\begin{aligned}
& \text { BW - Emulsion Arabic gum - day } 0 \\
& \text { BW - Emulsion Arabic gum - day } 6 \\
& \text { BW - Emulsion Pectin - day } 0 \\
& \text { BW - Emulsion Pectin - day } 6
\end{aligned}
$$

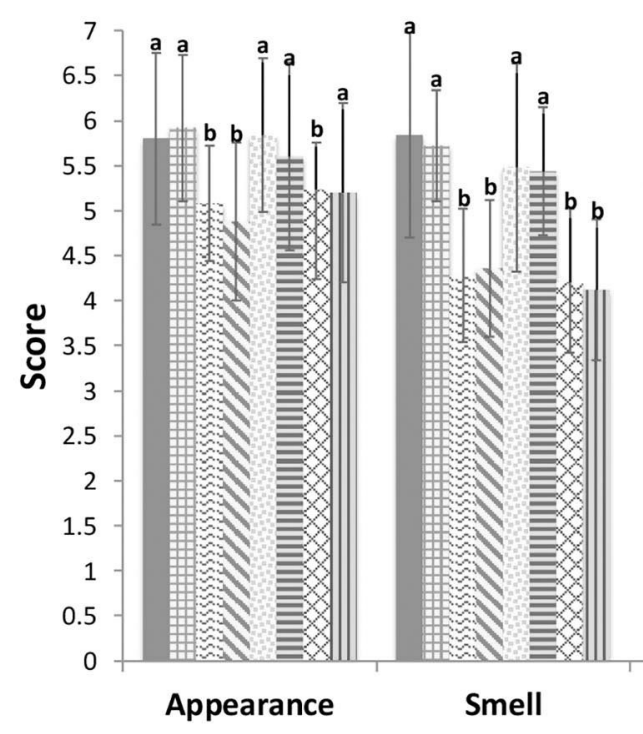

$$
\begin{aligned}
& \boxplus \text { BWO - Emulsion Arabic gum - day } 0 \\
& \text { BWO - Emulsion Arabic gum - day } 6 \\
& \equiv \text { BWO - Emulsion Pectin - Day } 0 \\
& \text { III BWO - Emulsion Pectin day } 6
\end{aligned}
$$

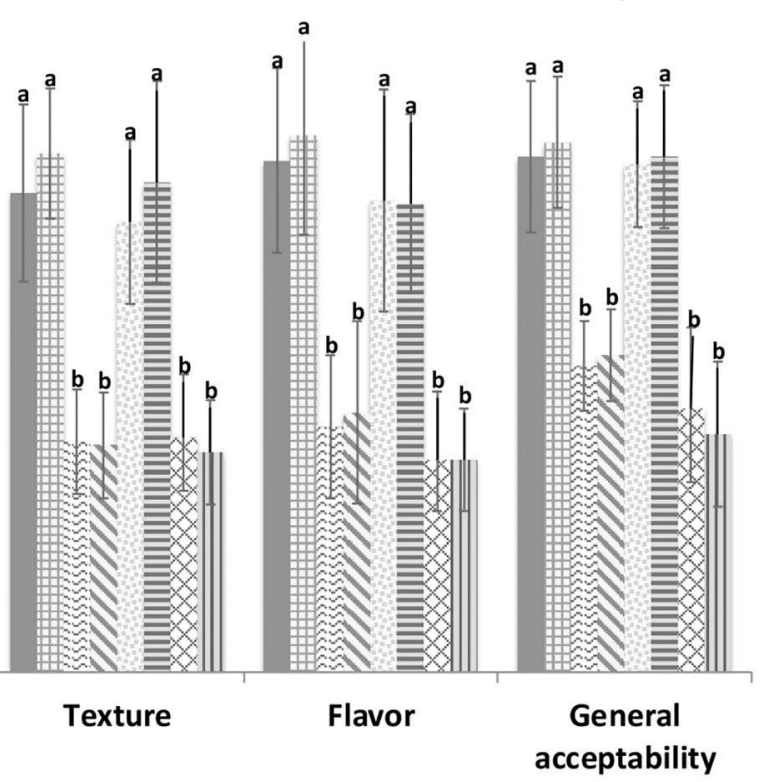

FIGURE 7 | Sensory analysis results of two bagel formulations, bagel-wheat flour (BW) and bagel-wheat flour-oats (BWO), sprayed with emulsions stabilized with pectin or Arabic gum at 10\% w/w (A) and 15\% w/w (B) of Mexican oregano essential oil (MOEO) evaluated on days 0 and 6 . Systems that do not share the same letter for the identical parameter are significantly different $(\rho<0.05)$. 
worked with breads made from a mixture of wheat flour and amaranth flour (3:1 mass ratio). Sanz (2011) did not observe a significant difference $(p>0.05)$ in the determination of hardness with respect to the control (bread made from wheat flour) after being stored for several days. However, when the mass ratio was $1: 1$, the hardness of the bread with amaranth flour was doubled, causing a significant difference $(p<0.05)$ between the samples of freshly baked breads. It has been reported that the addition of dietary fiber in bakery products can have an adverse effect on sensory acceptance, altering some of its characteristics, such as the increase in the hardness of the crumb, among others (Molina and Collar, 2008).

\section{Inhibition of Penicillium expansum}

The results observed in the present study could be because emulsions stabilized with pectin showed greater instability, since the particle size and the percentage of creaminess were higher than the ones for the emulsions stabilized with Arabic gum. As a result, MOEO in emulsions with pectin was diffused more quickly inward, decreasing the protection on the surface of the bagels. Although it was observed that even at high concentrations of MOEO in emulsions with Arabic gum or with pectin, over time, the growth of $P$. expansum increased rapidly and became equal to that of emulsions with a low concentration of MOEO; this phenomenon occurred from day 13.

For the different formulations of bagels (BW and BWO) atomized with emulsions stabilized with Arabic gum and different MOEO concentrations $(7.5 \%, 10 \%$, or $15 \% \mathrm{w} / \mathrm{w})$, growth of $P$. expansum occurred earlier in the BWO systems. Therefore, it can be inferred that oats favored the growth of $P$. expansum. These results coincide with the ones reported by Kamaljit et al. (2011) who evaluated the shelf life of breads made with wheat flour added with different percentages $(0 \%, 1 \%, 2 \%$, $3 \%, 4 \%$, or $5 \%$ ) of fiber (oats), which was packed in polyethylene bags and stored at a temperature of $19^{\circ} \mathrm{C}$ to $23^{\circ} \mathrm{C}$. These authors found that breads with the highest levels of oat-fiber showed microbial growth on the surface $24 \mathrm{~h}$ before the control system.

Portillo-Ruiz et al. (2012) evaluated in vitro the antimicrobial activity of MOEO (Lippia berlandieri Schauer) on the growth of Rhizopus spp., Aspergillus spp., and Penicillium spp. in wheat flour model systems with MOEO concentrations in a range of 50 to $200 \mathrm{ppm}$. These authors obtained the inhibition at 150 ppm of MOEO for Rhizopus spp. and Aspergillus spp., while for Penicillium spp., $200 \mathrm{ppm}$ were necessary. These MOEO concentrations were lower compared to those in the present study, since $10 \%$ and $15 \%$ w/w of MOEO with both encapsulating agents (pectin and Arabic gum) correspond to 375 and 562.5 ppm, respectively. In another study carried out by Viuda-Martos et al. (2007), these authors obtained results very similar to those of Portillo-Ruiz et al. (2012), since 207.33 ppm of MOEO were sufficient to achieve the inhibition of Aspergillus niger in model systems; additionally, they found that MOEO was more effective as an antimicrobial agent than essential oils of thyme and clove. The differences between the results reported by other authors and the present study are to be expected, since in in vitro studies, the antimicrobial activity of essential oils is achieved at lower levels than in in situ ones due to the complexity of in situ systems.
For bakery products, the approved preservatives commonly used are benzoates and sorbates. According to the Codex Alimentarius (2019), the maximum level added in bakery products permitted for these preservatives are 1,000 ppm. Essential oils are considered additives generally recognized as safe (GRAS), and there is no permissible level established, like the ones for benzoates and sorbates; therefore, its use is under good manufacturing practices (CFR, 2019).

\section{Mathematical Modeling of the Probability of Microbial Growth}

In the logit function used in the binary logistic regression, positive coefficients indicate that the event becomes more likely. The factor that had the highest positive coefficient was time for both models, followed by the interaction between concentration of $\mathrm{MOEO} *$ time. As seen in the prediction of the growth probability of $P$. expansum, as time increases, the odds for $P$. expansum growth increases as well; meanwhile, in the interaction between concentration of $\mathrm{MOEO} *$ time, as concentration of MOEO and time increase, the odds for $P$. expansum to growth is delayed. This prediction corresponds to the results observed in the experimental analysis. Since the concentrations of MOEO only inhibit the growth of $P$. expansum on the surface of the two formulations of bagels (BW and BWO), P. expansum will tend to grow after a certain amount of time.

Since the goodness of fit using the Hosmer and Lemeshow test had a chi-square $>0.99$ and a percentage of agreement of $>98 \%$ for the binary logistic regression models obtained for the microbial growth of $P$. expansum on the surface of two formulations of bagels (BW and BWO) atomized with emulsions stabilized with pectin or Arabic gum, these models could be used to predict the mold growth on this type of breads.

\section{Sensory Analysis}

The aging of the breads due to physicochemical deterioration is manifested mainly in alterations in the texture (loss of moisture of the crumb and softening of the crust) and changes in flavor and aroma (Pomeranz, 1987; Schiraldi and Fessas, 2001; Badui, 2006). These were perceived by the judges for almost all systems studied after 6 days of storage, except for the BWO systems atomized with emulsions stabilized with Arabic gum and 15\% w/w of MOEO. This behavior could be mainly attributed to two aspects. The first is related to the scores given by the judges to appearance, which was the least affected. The second aspect is related to the application of the emulsion, since it was observed empirically. Once the emulsion was absorbed on the surface of the bagels, their brightness was increased and continued until the maximum observation time (8 days). Although the brightness was not the same as that of a freshly atomized bread, it led the judges to believe that it was a freshly baked bread.

\section{CONCLUSIONS}

Encapsulation by emulsification using Arabic gum as an encapsulating agent allows the protection of oregano essential oil 
(MOEO) against instability mechanisms such as phase separation and oxidation. Encapsulating agents and the concentration of MOEO affected the physicochemical properties of the emulsions, Arabic gum systems being more stable than pectin ones. In addition, systems with more concentration of MOEO increased the physicochemical properties studied. The atomization of MOEO emulsions on the surface of two bagel formulations, BW and BWO, did not affect the physicochemical properties of the breads. MOEO (Lippia berlandieri Schauer) encapsulated by emulsification delayed the growth of $P$. expansum for up to 5 or 6 days at the highest concentrations evaluated $(10 \%$ and $15 \% \mathrm{w} / \mathrm{w} ; 375$ and $562.5 \mathrm{ppm}$, respectively) using Arabic gum as encapsulating agent, applied on the surface of a BW bagel. Binary logistic regression models proposed to predict the probability growth of $P$. expansum on the surface of two formulations of bagels (BW and BWO) demonstrated a good fitness to the experimental data. For sensory analysis, BW and BWO bagels atomized with MOEO emulsions at the highest concentrations studied were well-accepted by the panel of judges when these were evaluated on day 0 (freshly baked bread), not so when evaluated 6 days after their elaboration. MOEO encapsulated by emulsification could be an alternative antimicrobial agent; however, it is necessary to carry out further in situ studies of the different encapsulation techniques in food preservation.

\section{REFERENCES}

AACC (2000). Approved Methods of Analysis. St. Paul, MN: AACC International. AOA. (1995). Official methods of Analysis of AOAC. International: Food Composition, Additives, Natural Contaminants. A.O.A.C. International.

Asensio, C. M., Nepote, V., and Grosso, N. R. (2011). Chemical stability of extravirgin olive oil added with oregano essential oil. J. Food Sci. 76, 445-450. doi: 10.1111/j.1750-3841.2011.02332.x

Badui, D. (2006). Química de Los Alimentos, 4th Edn.Mexico City: Pearson Educación.

Baik, M. Y., and Chinachoti, P. (2000). Moisture redistribution and phase transitions during bread staling. Cereal. Chem. 77, 484-488. doi: 10.1094/CCHEM.2000.77.4.484

Bakry, A., Abbas, S., Ali, B., Majeed, H., Abouelwafa, M., Mousa, A., and Liang, L. (2016). Microencapsulation of oils: a comprehensive review of benefits, techniques, and applications. Compr. Rev. Food Sci. 15, 143-182. doi: 10.1111/1541-4337.12179

Balinska, M. (2009). The Bagel: The Surprising History of a Modest Bread. Cornwall: Yale University Press Publications.

Barbosa-Cánovas, G. V., Fontana, A. J., Schmidt, S. J., and Labuza, T. P. (2007). Water Activity en Foods. Fundamentals and Applications. Iowa: IFT Press and Blacwell Publishing. doi: 10.1002/9780470376454

Briceño, M. J., and Navas, H. P. (2005). Comparación de las características, físicas y perfil de ácidos grasos de los aceites de seje, oliva, maíz y soja. Revis. Facult. Agron. 31, 109-119.

CFR (2019). Code of Federal Regulations Title 21. Part 182. Substances Generally Recognized as Safe, 21 C.F.R. \$ 182.20. Available online at: https://www. accessdata.fda.gov/scripts/cdrh/cfdocs/cfcfr/CFRSearch.cfm?CFR/penalty\@MPart=182 (accessed August, 2020).

Chaquilla, Q. G., Torres, M. V., Ballinas, C. M., Gastélum, F. G., Silva, V. R., and Nevárez-Moorillón, V. (2007). Actividad antioxidante del aceite esencial de orégano mexicano (Lippia berlandieri Schauer) en sistemas alimenticios. Tercera Reunión Nacional Sobre Orégano. From August 22 to 24, 2007. Saltillo.

\section{DATA AVAILABILITY STATEMENT}

The datasets generated for this study are available on request to the corresponding author.

\section{AUTHOR CONTRIBUTIONS}

AS-N conducted the experiments and wrote part of the manuscript draft. $\mathrm{RH}-\mathrm{N}$ wrote the manuscript draft. MJ-M designed the study, analyzed data, and revised the manuscript. AL-M participated in analyzing results and revising the manuscript. All authors contributed to the article and approved the submitted version.

\section{ACKNOWLEDGMENTS}

The Authors acknowledge the National Council for Science and Technology (CONACyT) of Mexico (Fondo Sectorial de Investigación SRE-CONACYT Grant Numbers 278343 and CB-2016-01-283636) and Universidad de las Americas Puebla (UDLAP) for the grants received for this research. AS-N and RH-N acknowledge UDLAP and the Consejo Nacional de Ciencia y Tecnología (Conacyt, Mexico) for the financial support toward their master's degree and Ph.D. studies, respectively, in Food Science.
Charoen, R., Jangchud, A., Jangchud, K., Harnsilawat, T., Naivikul, O., and McClements, D. J. (2011). Influence of biopolymer emulsifier type on formation and stability of rice bran oil-in-water emulsions: whey protein, gum arabic, and modified starch. J. Food Sci. 76, E165-E172. doi: 10.1111/j.1750-3841.2010.01959.x

Chew, N., and Chan, H. K. (2002). Effect of powder polydispersity on aerosol generation. J. Pharm. Pharm. Sci. 5, 162-168.

Codex Alimentarius (2019). General Standard for Food Additives (CODEX STAN 192-1995). Retrieved from: http://www.fao.org/fao-who-codexalimentarius/ home/en/ (accessed August, 2019).

Cosme, A. L., Guerrero, J. A., and Vélez, J. F. (1997). Evaluación de propiedades fisicoquímicas de leche concentrada. Inform. Tecnol. 8, 35-40.

Dávila-Rodríguez, M., López-Malo, A., Palou, E., Ramirez-Corona, N., and Jimenez-Munguia, M. T. Essential oils microemulsions prepared with highfrequency ultrasound: physical properties and antimicrobial activity. J. Food Sci. Technol. (2020) 57, 4133-4142. doi: 10.1007/s13197-020-04449-8

Demetriades, K., and McClements, D. J. (2000). Influence of sodium dodecyl sulfate on the physico-chemical properties of whey proteinstabilized emulsions. Colloid Surf. A Physicochem. Eng. Asp. 161, 391-400. doi: 10.1016/S0927-7757(99)00210-1

Djordjevic, D., Cercaci, L., Alamed, J., McClements, D. J., and Decker, E. A. (2007). Chemical and physical stability of citral and limonene in sodium dodecyl sulfate-chitosan and gum arabic-stabilized oil-in-water emulsions. J. Agr. Food Chem. 55, 3585-3591. doi: 10.1021/jf063472r

Dobson, A. J. (1990). An Introduction to Statistical Modelling. London: Chapman and Hall Ltd.

Dziezak, J. D. (1991). A focus on gums. Food Technol. 45, 115-132.

Geankoplis, C. J. (1998). Procesos de Transporte y Principios de Procesos de Separación, 3rd Edn. Mexico: CECSA.

Güzey, D., and McClements, D. J. (2006). Influence of environmental stresses on $\mathrm{O} / \mathrm{W}$ emulsions stabilized by $\beta$-Lactoglobulin-Pectin and $\beta$-lactoglobulinpectin-chitosan membranes produced by the electrostatic layer-by-leyer deposition technique. Food Biophys. 1, 30-40. doi: 10.1007/s11483-005-9002-z 
Janiszewska, E., and Witrowa-Rajchert, D. (2009). The influence of powder morphology on the effect of rosemary aroma microencapsulation during spray drying. Int. J. Food Sci. Tech. 44, 2438-2444. doi: 10.1111/j.1365-2621.2009.02025.x

Kamaljit, K., Amarjeet, K., and Tarvinder, P. (2011). Analysis of ingredients, functionality, fomulation optinization and shelf life evaluations of high fiber bread. Am. J. Food Technol. 6, 306-313. doi: 10.3923/ajft.2011.306.313

Lakkis, J. M. (2007). Encapsulation and Controlled Release Technologies in Food Systems. Iowa: Blackwell Publishing. doi: 10.1002/9780470277881

Larmond, E. (1982). Laboratory Metohods for Sensory Evaluation of Food. Minister of Supply and Services Canada.

Leroux, J., Langendorff, V., Schick, G., Vaishnav, V., and Mazoyer, J. (2003). Emulsion stabilizing properties of pectin. Food Hydrocoll. 17, 455-62. doi: 10.1016/S0268-005X(03)00027-4

López, M. B., Carvajal, P. L., and Millán, C. L. (2009). Establishing of the conditions of the blend of pulp with banana (Musa paradisiaca l.) to submit spray dryng. Vitae 16.

Madjouko, M. A., Tchameni, S. N., Tchinda, E. S., Dongmo-Jazet, P. M., Noumegna-Kamsu, P., Souop-Kamga, V. A. M., et al. (2019). Inhibitory effects of essential oils from Ocimum basilicum and Ocimum gratissimum on Colletotrichum musae: the causal agent of bananas anthracnose. J. Phytopathol. 167, 257-264. doi: 10.1111/jph.12793

McClements, D. J. (2005). Food Emulsions: Principles, Practice, and Techniques, 2nd Edn. Boca Raton, FL: CRC Press. doi: 10.1201/9781420039436

Meilach, D. Z. (1995). The Best Bagels are Made at Home. Hayward: Bristol Publishing Enterprises.

Molina, R. M., and Collar, E. C. (2008). Patent Composición de fibras para la obtención de productos bajos en calorías y ricos en fibras. World Intellectual Property Organization. International Publication Number WO 2008/000883 A1.

Moore, M. M., Dal Bello, F., and Arendt, E. K. (2008). Sourdough fermented by Lactobacillus plantarum FST 1.7 improves the quality and shelf life of gluten-free bread. Eur. Food Res. Technol. 226, 1309-1316. doi: 10.1007/s00217-007-0659-z

Moreno, M. A. (2011). Formación de emulsiones asistida con ultrasonido. Bachelor's degree thesis. Engineering School. Department of Chemical, Food and Environmental Engineering. Mexico: Universidad de las Américas Puebla.

Ortuño, S. M. (2006). Practical Handbook of Essential Oils, Flavors and Fragrances. Spain: Aryana.

Paraskevopoulou, D., Boskou, D., and Paraskevopoulou, A. (2007). Oxidative stability of olive oil-lemon juice salad dressings stabilized with polysaccharides. Food Chem. 101, 1197-1204. doi: 10.1016/j.foodchem.2006.03.022
Phillips, G. O., and Williams, P. A. (2009). Handbook of Hydrocolloid, 2nd Edn. CRC Press and Woodhead Publishing Ltd. doi: 10.1533/9781845695873

Piazza, L., and Masi, P. (1995). Moisture redistribution throughout the bread loaf during staling and its effect on mechanical properties. Cereal Chem. $72,320-325$.

Pomeranz, Y. (1987). Modern Cereal Science and Technology. New York, NY: VCH Publishers Inc.

Portillo-Ruiz, M. C., Ávila-Sosa, S. R., Viramontes, R. S., Torres, M., and Nevárez-Moorillón, G. V. (2012). Antifungal effect of mexican oregano (Lippia berlandieri Schauer) essential oil on a wheat flour-based medium. J. Food Sci. 77, 441-445. doi: 10.1111/j.1750-3841.2012.02821.x

Qian, C., Decker, E. A., Xiao, H., and McClements, D. J. (2011). Comparison of biopolymer emulsifier performance in formation and stabilization of orange oil-in-water emulsions. J. Am. Oil. Chem. Soc. 88, 47-55. doi: 10.1007/s11746-010-1658-y

Robertson, G. (2003). Food Packaging. Principles and Practice, 2nd Edn. Boca Raton, FL: CRC Press.

Sandoval, A. A., Rodríguez, S. E., and Ayala, A. A. (2004). Encapsulación de aditivos para la industria de alimentos. Ingeniería y Competitividad. 5, 73-84. doi: 10.25100/iyc.v5i2.2298

Sanz, P. N. (2011). Desarrollo de panes especiales con harina integral de amaranto (Master's degree thesis). Universidad Politécnica de Valencia. Spain.

Schiraldi, A., and Fessas, D. (2001). Bread Staling: Mechanism of Staling, 1st Edn. Boca Raton, FL: CRC Press. doi: 10.1201/9781420036671.ch1

Stanley, P., Cauvain, S. P., and Young, L. S. (2007). Technology of Bread Making, 2nd Edn. New York, NY: Springer Science and Business Media.

Viuda-Martos, M., Ruiz-Navajas, Y., Fernández-López, J., and PérezÁlvarez, J. A. (2007). Antifungal activities of thyme, clove and oregano essential oils. J. Food Saf. 27, 91-101. doi: 10.1111/j.1745-4565.2007. 00063.x

Conflict of Interest: The authors declare that the research was conducted in the absence of any commercial or financial relationships that could be construed as a potential conflict of interest.

Copyright (C) 2020 Salgado-Nava, Hernández-Nava, López-Malo and JiménezMunguia. This is an open-access article distributed under the terms of the Creative Commons Attribution License (CC BY). The use, distribution or reproduction in other forums is permitted, provided the original author(s) and the copyright owner(s) are credited and that the original publication in this journal is cited, in accordance with accepted academic practice. No use, distribution or reproduction is permitted which does not comply with these terms. 